\title{
Comparative Study between Ultrasound-Guided Serratus Anterior Plane Block and Thoracic Epidural Analgesia for Breast Surgery
}

Ahmed Elsaied Abd-EIrahman Ali ${ }^{1}$, Sherif Kamal Hafez Arafa ${ }^{2}$, Amir Abou Zkry Elsayed ${ }^{2}$, Mahmoud Fawzy Shehata El Sharkawy*4

${ }^{1}$ Department of Anesthesia and Intensive Care and Pain Medicine, Faculty of Medicine, Sohag University, Sohag,

${ }^{2}$ Department of Anesthesia and Intensive Care, Faculty of Medicine, Kafr Elsheikh University, Kafr Elsheikh,

${ }^{4}$ Department of Anesthesia and Intensive Care, Faculty of Medicine, Aswan University, Aswan, Egypt

*Corresponding author: Mahmoud Fawzy Shehata, Mobile: (+20) 01011774192, E-Mail: mahmoud83me@gmail.com

\begin{abstract}
Background: Breast surgery is a common procedure and associated with an increased incidence of acute and chronic pain. These procedures cause significant acute pain and may progress to chronic pain states in 25-60\% of cases. Regional anesthesia techniques may improve postoperative analgesia for patients undergoing breast surgery.

Objective: To compare the difference between the anesthetic effect of thoracic epidural versus serratus anterior plane block in breast surgery.

Patients and methods: This study conducted on 60 adult patients scheduled for elective breast surgery divided into three groups. Each group contains twenty patients. Group A (n. 20) received general anesthesia only, Group B (n. 20) received combined general anesthesia and thoracic epidural analgesia, by receiving $6-8 \mathrm{ml}$ of $0.25 \%$ bupivacaine and $0.05 \mathrm{mg}$ fentanyl via the epidural catheter and Group C (n. 20) received serratus anterior plane block combined with general anesthesia.
\end{abstract}

Results: The results of the present study demonstrated that SAP block caused hemodynamic stability, decreased the intensity of postoperative pain, reduced postoperative analgesic requirement, prolonged the time needed for the first request of analgesia, Therefore it can be considered as a safe procedure and effective for intraoperative and postoperative pain control in breast surgeries. Also, this study demonstrated that there is no difference between the groups according to nausea and vomiting.

Conclusion: SAP block can produce excellent pain relief during the first six postoperative hours. It has a great promise due to its simplicity, easy-to-learn techniques, and relative lack of contraindications and complications.

Keywords: Ultrasound, Serratus Anterior Plane Block, Thoracic Epidural Analgesia, Breast Surgery

\section{INTRODUCTION}

Anesthesiologists are very concerned about alleviating postoperative pain in general and especially after breast surgery. Regional blocks guided by ultrasonography such as thoracic epidural block and pectoral nerve block are recommended. That is because breast surgery, even relatively minor, can be associated with significant postoperative pain ${ }^{(\mathbf{1})}$.

Postoperative pain for surgeries involving chest wall is mostly managed using multimodal analgesia by using a combination of non-steroidal anti-inflammatory drugs (NSAIDs), paracetamol, opioids, and local anesthetic infiltration. In extensive surgeries like radical mastectomy and latissimus dorsi flaps, some anesthetists may employ the use of thoracic epidural analgesia or paravertebral blocks, or pectoral nerves block (2).

Epidural anesthesia represents one of the central neuraxial block techniques. Improvements in equipment, drugs, and technique made it a popularity and introduced it as a versatile anesthetic technique with many applications in surgery and pain control ${ }^{(3)}$.

Blanco et al. ${ }^{(4)}$, first described a new block of the thoracic wall serratus plane block under Ultra Sound guidance. Local Anesthesia was deposited in the Serratus Anterior Plane. The lateral cutaneous branches of the intercostal nerves, before dividing into anterior and posterior branches are blocked as they pass through

this plane to supply sensation to the anterolateral chest wall. This novel technique has become a popular analgesic alternative to multiple puncture intercostals block, epidural and paravertebral block in breast surgery given decreased incidence of adverse events and has the advantage of the simultaneous blockade of multiple dermatomes, it is easy to do and decrease the rate of local anesthetic absorption ${ }^{(5)}$.

The great advances achieved in the pain management of breast cancer surgery have made it essential for the anesthesiologist to have detailed knowledge of all anatomical features of the breast, thoracic wall, and axillary region, especially with the increasing use of ultrasonography to identify tissue layers and particularly, fascial layers has led to the development of several newer interfascial injection techniques for analgesia of the chest and abdominal wall (6).

Over the past decade, the physical and clinical understanding of anatomical sonography has evolved greatly. Ultrasound guidance enables the anesthetist to secure an accurate needle position and to monitor the distribution of the local anesthetic in real-time and this 
improves the quality and helps to avoid the complications of nerve blocks ${ }^{(7)}$.

This study aims to compare the difference between the anesthetic effect of thoracic epidural versus serratus anterior plane block in breast surgery.

\section{PATIENTS AND METHODS}

This is a prospective randomized clinical study done at Aswan University Hospitals after approval of the departmental ethical committee, informed consent was obtained from every patient. Any unexpected risks that appeared during the research will be cleared to participants and the ethical committee on time and proper measures will be taken to overcome or minimize these risks.

This study conducted on $\mathbf{6 0}$ adult patients scheduled for elective breast surgery divided into three groups. Each group contains twenty patients.

- Group A (n. 20) received general anesthesia only

- Group B (n. 20) received combined general anesthesia and thoracic epidural analgesia, by receiving $6-8 \mathrm{ml}$ of $0.25 \%$ bupivacaine and $0.05 \mathrm{mg}$ fentanyl via the epidural catheter

- Group C (n. 20) received serratus anterior plane block combined with general anesthesia

\section{Inclusion criteria:}

- Age: 20-50 years old with breast cancer undergone breast surgery

- Sex: female

- (ASA): I-II

- Operation: simple mastectomy

\section{Exclusion criteria:}

- ASA: III-IV

- Patient refusal

- Contraindications to regional anesthesia (as coagulopathy,......).

- Allergy to local anesthetics or opioids

- The patient who had coronary or peripheral artery disease, Nerve disease

- Thoracic vertebra anomaly

- Failed cases (failure of the sensory level block).

- Respiratory and cardiac disorder

- Bilateral breast cancer

- Morbid obese with comorbidities

- Hepatic patient (bleeding disorder).

\section{Preoperative visit:}

One day before surgery all patients were interviewed to explain the visual analog scale (VAS), which is designed to present to the respondent a rating scale in which the respondents mark the location on the 10-centimeter line corresponding to the amount of pain they experienced. This gives them the greatest freedom to choose their pain's exact intensity. It also allows for each respondent to express a personal response style.
Also, routine investigations in the form of twelve leads electrocardiography (ECG), complete blood count (CBC), coagulation profile (bleeding time, prothrombin time, international normalized ratio, and partial thromboplastin time), liver functions, kidney functions, and random blood sugar were fulfilled.

On the day of surgery, we also checked if there has been any recent change in the patient's condition or therapy particularly one that might affect the surgical event:

- Check that the patient has taken his regular medications.

- Check that the patient fasting for six hours.

- Confirm that the patient has been well since the preoperative assessment visit and does not have any acute illness such as an upper respiratory tract infection.

- Blood pressure rechecked during preoperative assessment.

- Standard patient monitoring was attached to the patient and an IV access was inserted.

\section{Techniques:}

One hour before surgery, Intravenous access was established, and all patients were premedicated with midazolam $0.02 \mathrm{mg} / \mathrm{kg}$.

\section{Thoracic epidural:}

In the sitting position, after injection of local anesthesia, a midline thoracic epidural was performed at the T6/T7 interspinous space using a size 18G Tuohy epidural needle and loss of resistance to air technique. The skin epidural depth was $5 \mathrm{~cm}$, and $4 \mathrm{~cm}$ of the epidural catheter was left in situ in the epidural space in the cephalad direction, and the catheter adhered to the back with adhesive tape. The epidural catheter was connected to a syringe pump for continuous infusion. After upper sensory block up to the T6 level has been confirmed all study patients received $1-2 \mathrm{mg} / \mathrm{kg}$ of propofol followed by $0.5 \mathrm{mg} / \mathrm{kg}$ of atracurium and $1-2$ $\mu \mathrm{g} / \mathrm{kg}$ fentanyl. They intubated, and anesthesia maintained with $1-1.5 \%$ isoflurane in $50 \%$ oxygen and $50 \%$ air Intraoperative muscle relaxation maintained by atracurium $0.1 \mathrm{mg} / \mathrm{kg}$ every $20 \mathrm{~min}$. Epidural continuous infusion started after induction of general anesthesia as $0.125 \%$ bupivacaine and fentanyl at a dose of $1.5 \mu \mathrm{g} / \mathrm{ml}$ at a rate of $0.1 \mathrm{ml} / \mathrm{kg} / \mathrm{h}$ in Group B. The infusions continued throughout the surgical procedure.

\section{Serratus anterior plane block (SAPB):}

Serratus anterior plane block done under sterile conditions and while patients in the lateral position with the diseased side up, a linear ultrasound transducer (10$12 \mathrm{MHz}$ ) placed in a sagittal plane over the midclavicular region of the thoracic cage. Then the ribs counted down until the fifth rib identified in the midaxillary line, the following muscles identified overlying the fifth rib the latissimus dorsi (superficial and posterior), teres major (superior), and serratus muscles (deep and inferior). The needle (a22-gauge, 50$\mathrm{mm}$ Touhy needle) introduced in-plane concerning the 
ultrasound probe targeting the plane superficial to the serratus anterior muscle Under continuous ultrasound guidance, $30 \mathrm{ml}$ of $0.25 \%$ bupivacaine injected, and then a catheter threaded continuous infusion of $5 \mathrm{ml} /$ hour of $0.125 \%$ bupivacaine started through the catheter after that the patient received $1-2 \mathrm{mg} / \mathrm{kg}$ of propofol followed by $0.5 \mathrm{mg} / \mathrm{kg}$ of atracurium and $1-2 \mu \mathrm{g} / \mathrm{kg}$ fentanyl. They intubated, and anesthesia maintained with 1-1.5\% isoflurane in $50 \%$ oxygen and $50 \%$ air Intraoperative muscle relaxation maintained by atracurium $0.1 \mathrm{mg} / \mathrm{kg}$ every $20 \mathrm{~min}$.

\section{Ethical Considerations:}

Approval of the study was obtained from Aswan University academic and ethical committee. Every patient signed informed written consent for the acceptance of the operation.
Recorded data were analyzed using the statistical package for social sciences, version 20.0 (SPSS Inc., Chicago, Illinois, USA). Quantitative data were expressed as mean \pm standard deviation (SD). Qualitative data were expressed as frequency and percentage. Chi-square (x2) test of significance was used to compare proportions between two qualitative parameters. The confidence interval was set to $95 \%$ and the margin of error accepted was set to $5 \%$. A pvalue $<0.05$ is considered statistically significant.

\section{RESULTS}

Data from 60 female patients in three groups each group is 20 scheduled for breast surgeries were analyzed.

Patients' demographics concerning age, body weight, height, and BMI had no significant difference between the studied groups. Table 1 .

\section{Statistical Analysis:}

Table (1): Comparison between groups according to demographic data

\begin{tabular}{|c|c|c|c|c|}
\hline & Group A & Group B & Group C & P-value \\
\hline $\begin{array}{l}\text { Age } \\
\text { Mean } \pm \text { SD } \\
\text { Range }\end{array}$ & $\begin{array}{c}30.6 \pm 8.6 \\
20-45\end{array}$ & $\begin{array}{c}34.7 \pm 8.18 \\
22-50\end{array}$ & $\begin{array}{c}34.7 \pm 8.18 \\
22-50\end{array}$ & 0.207 \\
\hline $\begin{array}{l}\text { Weight } \\
\text { Mean } \pm S D \\
\text { Range }\end{array}$ & $\begin{array}{c}76.6 \pm 6.82 \\
65-85\end{array}$ & $\begin{array}{c}74.2 \pm 6.52 \\
65-85\end{array}$ & $\begin{array}{c}76.3 \pm 6.87 \\
65-85\end{array}$ & 0.475 \\
\hline $\begin{array}{l}\text { Height } \\
\text { Mean } \pm \text { SD }\end{array}$ & $1.68 \pm 0.08$ & $1.69 \pm 0.08$ & $1.71 \pm 0.05$ & 0.550 \\
\hline $\begin{array}{l}\text { BMI } \\
\text { Mean } \pm \text { SD }\end{array}$ & $27.13 \pm 2.09$ & $25.98 \pm 2.32$ & $26.24 \pm 2.08$ & 0.217 \\
\hline
\end{tabular}

Analysis of quantitative data by independent t-test.

Analysis of qualitative data by chi-squared test.

there was no statistically significant difference found between the studied groups at baseline values $(\mathrm{P}$-value $>$ 0.05) while there highly statistically significant decrease from after block to 15 min after block in was a group B compared with group $\mathrm{C}(\mathrm{P}$-value $<0.006)$ and a statistically significant decrease at $1 \mathrm{hr}$ after block $(\mathrm{P}$-value $<0.011)$. So, heart rate increase after skin incision in group A more than group B more than group $\mathrm{C}$ and decrease after one hour in group $\mathrm{C}$ more than $\mathrm{B}$ and A. Table 2.

Table (2): Heart rate distribution between 3 groups

\begin{tabular}{|l|c|c|c|c|}
\hline \multirow{2}{*}{ HR } & Group A & Group B & Group C & \multirow{2}{*}{ P-value } \\
\cline { 2 - 4 } & Mean \pm SD & Mean \pm SD & Mean \pm SD & \\
\hline Baseline & $70.5 \pm 7.26$ & $70.05 \pm 6.72$ & $71.05 \pm 6.47$ & 0.898 \\
\hline 5 min & $71 \pm 7.28$ & $70.9 \pm 5.97$ & $71.1 \pm 6.5$ & 0.995 \\
\hline After skin incision & $75.5 \pm 4.59$ & $70.85 \pm 5.51$ & $70.7 \pm 5.97$ & $0.009^{* *}$ \\
\hline $15 \mathrm{~min}$. & $75.45 \pm 4.57$ & $69.35 \pm 6.68$ & $71.35 \pm 6.12$ & $0.006^{* *}$ \\
\hline $1 \mathrm{hr}$ & $74.7 \pm 4.27$ & $69.05 \pm 6.55$ & $70.95 \pm 6.32$ & $0.011^{*}$ \\
\hline End of surgery & $71.05 \pm 6.04$ & $71.35 \pm 5.71$ & $70.95 \pm 6.32$ & 0.976 \\
\hline
\end{tabular}

The baseline mean MAP was $(89.9 \pm 4.89) \mathrm{mmHg}$ in group B and $(89.10 \pm 3.78) \mathrm{mmHg}$ in group C which showed no statistical difference among the two studied groups (P-value > 0.05). The mean MAP was recorded After the block, After induction, $15 \mathrm{~min}$. after block, $1 \mathrm{hr}$ after block, at the end of surgery and there was a highly statistically significant decrease in mean MAP in group B than group C from after block to $15 \mathrm{~min}$ after block $(\mathrm{P}$-value $<0.008)$. Table 3. 
Table (3): MAP distribution between 3 groups

\begin{tabular}{|l|c|c|c|c|}
\hline \multirow{2}{*}{ MAP } & Group A & Group B & Group C & \multirow{2}{*}{ P-value } \\
\cline { 2 - 5 } & Mean \pm SD & Mean \pm SD & Mean \pm SD & \\
\hline Baseline & $89.25 \pm 5.25$ & $89.9 \pm 4.89$ & $89.25 \pm 5.25$ & 0.899 \\
\hline 5 min. & $88.55 \pm 5.51$ & $90.4 \pm 4.3$ & $87.75 \pm 4.61$ & 0.214 \\
\hline After skin incision & $91.5 \pm 2.35$ & $87.75 \pm 4.61$ & $89.05 \pm 5.13$ & $0.022^{*}$ \\
\hline 15 min. & $91.2 \pm 2.12$ & $87.05 \pm 4.43$ & $88.15 \pm 5.38$ & $0.008^{* *}$ \\
\hline $1 \mathrm{hr}$ & $88.55 \pm 5.51$ & $89.05 \pm 5.14$ & $89.9 \pm 4.88$ & 0.708 \\
\hline End of surgery & $89.05 \pm 5.14$ & $89.25 \pm 5.25$ & $89.7 \pm 4.79$ & 0.917 \\
\hline
\end{tabular}

VAS pain scores throughout the first $24 \mathrm{hrs}$ postoperative showed that there was a highly statistically significant decrease in VAS in immediate till 6hrs postoperative in SAPB group (VAS in group C less than in group A, B). (P-value $<0.001)$. Table 4.

Table (4): Comparison between groups according to VAS

\begin{tabular}{|l|c|c|c|c|}
\hline \multirow{2}{*}{ VAS } & Group A & Group B & Group C & \multirow{2}{*}{ P-value } \\
\cline { 2 - 4 } & Mean \pm SD & Mean \pm SD & Mean \pm SD & \\
\hline $0 \mathrm{~min}$ & $7.3 \pm 1.66$ & $1.1 \pm 0.72$ & $0.8 \pm 0.62$ & $<\mathbf{0 . 0 0 1} * *$ \\
\hline $2 \mathrm{hr}$ & $6.3 \pm 1.66$ & $1.65 \pm 0.67$ & $1.25 \pm 0.55$ & $<\mathbf{0 . 0 0 1} * *$ \\
\hline $4 \mathrm{hr}$ & $6 \pm 1.45$ & $5.15 \pm 0.75$ & $1.95 \pm 0.22$ & $<\mathbf{0 . 0 0 1} * *$ \\
\hline $6 \mathrm{hr}$ & $5 \pm 1.17$ & $6.15 \pm 0.75$ & $3.75 \pm 1.02$ & $<\mathbf{0 . 0 0 1} * *$ \\
\hline $8 \mathrm{hr}$ & $3.95 \pm 1.15$ & $5 \pm 0.65$ & $4.75 \pm 1.02$ & $<\mathbf{0 . 0 0 1} * *$ \\
\hline $12 \mathrm{hr}$ & $2.9 \pm 1.12$ & $2.95 \pm 0.6$ & $1.25 \pm 0.55$ & $<\mathbf{0 . 0 0 1} * *$ \\
\hline $24 \mathrm{hr}$ & $1.4 \pm 1.23$ & $1.65 \pm 0.93$ & $0.8 \pm 0.62$ & $\mathbf{0 . 0 2 1} *$ \\
\hline
\end{tabular}

As regard to Morphine consumption was investigated and the results showed that in the SAPB group reduced amount of Morphine consumption $(5.33 \pm 47 \mathrm{mg}$ ) during the first 24 hours postoperative while in TEA the amount was $(8.66 \pm 0.48 \mathrm{mg})$ and in general anesthesia, the amount was $(9.93 \pm 0.83 \mathrm{mg})$ with (a P-value < 0.001$)$. Morphine consumption in group $\mathrm{C}$ is decreased in comparison to other groups. Table 5.

Table (5): Total Morphine consumption distribution between 3 groups

\begin{tabular}{|c|c|c|c|c|}
\hline & Group A & Group B & Group C & \multirow{2}{*}{ P-value } \\
\cline { 2 - 4 } & Mean \pm SD & Mean \pm SD & Mean \pm SD & \\
\hline Total dose & $9.93 \pm 0.83$ & $8.66 \pm 0.48$ & $5.33 \pm 0.47$ & $<\mathbf{0 . 0 0 1 * *}$ \\
\hline
\end{tabular}

PONV was studied according to a 5-point scale (0-4), where $0=$ no nausea or vomiting, $1=$ mild nausea, $2=$ severe nausea, $3=$ vomiting once, and $4=$ vomiting more than once from the end of the procedure and showed no significant difference between groups AS in PACU there are 2 patients in group $\mathrm{C}$ have nausea and vomiting and 3 patients in group B have nausea and 4 patients in group A postoperative with (P-value 0.676) which is not statistically significant. Table 6.

Table (6): Nausea and vomiting distribution between 3 groups

\begin{tabular}{|l|c|c|c|c|c|c|c|}
\hline \multirow{2}{*}{} & \multicolumn{2}{|c|}{ Group A } & \multicolumn{2}{c|}{ Group B } & \multicolumn{2}{c|}{ Group C } & \multirow{2}{*}{ P-value } \\
\cline { 2 - 7 } & No. & $\mathbf{\%}$ & No. & \% & No. & \% & \multirow{2}{*}{0.676} \\
\hline Yes & 4 & 20.0 & 3 & 15.0 & 2 & 10.0 & \multirow{2}{*}{0.076 .0} \\
\hline No & 16 & 80.0 & 17 & 85.0 & 18 & 90.0 & \\
\hline
\end{tabular}

\section{DISCUSSION}

In this study pain scores assessed by VAS and the results showed that patients with SAPB were experienced less intense pain at $2 \mathrm{hrs}$, $4 \mathrm{hrs}$, and $6 \mathrm{hrs}$ postoperative than the TE group with a highly statistically significant decrease of VAS in the SAPB group with (a P-value < 0.001). This current study goes with Khalil et al. ${ }^{(8)}$ who compared the Ultrasoundguided serratus anterior plane block versus thoracic epidural analgesia for thoracotomy pain. Forty patients aged 20 to 60 years old with an American Society of Anesthesiologists physical status of class II and III, scheduled for thoracotomy under general anesthesia.
They were allocated randomly into 1 of 2 groups with 20 patients each. Patients in the SAPB group received general anesthesia, and before extubation, an ultrasoundguided SAPB was performed with the insertion of a catheter. Patients in the TEA group underwent thoracic epidural catheter fixation using the loss of resistance technique, before surgery while awake to avoid neural injury. In both groups, a loading dose of the local anesthetic solution was injected at the end of the surgical procedure. In the SAPB group, an injection of $30 \mathrm{~mL}$ of $0.25 \%$ levobupivacaine was given in the plane superficial to serratus anterior muscle then a continuous infusion of $5 \mathrm{~mL} /$ hour of $0.125 \%$ levobupivacaine was 
started through the catheter. In the TEA group, a loading dose of $15 \mathrm{~mL}$ of $0.25 \%$ levobupivacaine was given then a $5 \mathrm{~mL} /$ hour of $0.125 \%$ levobupivacaine infusion was started. Postoperative heart rate and MAP were recorded at 0,15 minutes, 30 minutes, 1 hour, and then every 2 hours for 24 hours. The VAS performed while patients were breathing quietly, were recorded as soon as the patient was alert enough to report pain, then every 2 hours for 24 hours. All patients received paracetamol, 1 $\mathrm{g} / 8$-hour, rescue analgesia using intravenous morphine, $0.1 \mathrm{~mL} / \mathrm{kg}$, was administered if the VAS was $>3$. The total 24-hour morphine consumption was recorded for every patient. The authors found that the mean arterial pressure in the SAPB group did not change significantly $(\mathrm{p}=0.181)$, whereas it decreased significantly $(\mathrm{p}=$ $0.006)$ in the TEA group. This is attributed to the autonomic block that accompanies paravertebral and epidural blocks which are not present in SAPB.

In the present study, the efficacy of the SAPB and TEA for analgesic consumption were investigated and the results showed that in the SAPB group reduced amount of morphine consumption $(5.33 \pm 47 \mathrm{mg})$ during the first 24 hours postoperative while in TEA the amount was $(8.66 \pm 0.48 \mathrm{mg})$ with (a P-value < 0.001$)$. Where an adequate VAS score of less than 3 was maintained by Paracetamol $1 \mathrm{gm}$ intravenous every 8 hours just after transferring toward for all patients. In agreement with this study, Zhou et al. ${ }^{(\boldsymbol{9})}$ found that the patients in the SAPB group required significantly lower total dosages of morphine and tramadol during their first postoperative hour in the PACU than the patients who received the standard pain control protocol.

Also in Arora et al. ${ }^{(\mathbf{1 0})}$ study, they found that Postoperative total Diclofenac consumption in the first $24 \mathrm{hrs}$ was less in SAPB Group (138.8 \pm 44.0$) \mathrm{mg}$ compared to TPVB Group $(210.0 \pm 39.2) \mathrm{mg}$ with (a P value of $<0.001)$. Also, this current study goes with Hards et al. ${ }^{(11)}$ who studied the effect of serratus plane block performed under direct vision on postoperative pain in breast surgery the study included 16 patients who had received a serratus block and 11 patients who only had wound infiltration with levobupivacaine with adrenaline and clonidine. Results demonstrated excellent pain control in patients who had received a serratus plane block under direct vision day 1 postoperatively compared to the control group with $81 \%$ experiencing mild pain or no pain at all. All these patients required no analgesia or only simple analgesia day 1 postoperatively

All of these studies and their results are due to the TE block produce a dense block of the T2-T6 spinal nerves and thereby the intercostal nerves and all lateral and anterior cutaneous branches but not anesthetize the LPN (C5-C7), the MPN (C8-T1), the long thoracic nerve (C 5-C 7) or the thoracodorsal nerve (C6- C8) that are blocked by SAPB leading to adequate analgesia.

In contrast to this work a study was done by Davies $\boldsymbol{e t} \boldsymbol{a l} .{ }^{(12)}$ and Júnior $\boldsymbol{e t} \boldsymbol{a l} .{ }^{(13)}$ they compared the analgesic efficacy of epidural blockade versus paravertebral for thoracotomy they found a nonsignificant difference in pain scores between PVB and epidural groups at $4-8$ or 24 hours in the postoperative period. Also, a study done by Soni $\boldsymbol{e t} \boldsymbol{a l}$. (14) found that the quality of analgesia in immediate and $1 \mathrm{hr}$ postoperative similar in the epidural and paravertebral groups. For the epidural group it was $(0.47 \pm 0.49)$ and $(1.2 \pm 1.24)$ respectively. In the paravertebral group, the values were $(0.53 \pm 0.56)$ and $(1.03 \pm 1.17)$ respectively. The $\mathrm{p}$-values were 0.323 and 0.304 respectively.

Additionally, we found that there was a significant prolongation in the duration of postoperative analgesia in the patients receiving the SAPB. The mean duration was $(360 \pm 25) \mathrm{min}$. in the SAPB group and $(240 \pm 25)$ min. in TE with (a P value of $<0.001)$. There was a limitation for the maximum duration for the SAPB group by the $6 \mathrm{hrs}$. postoperative and there was a significant difference between the SAPB group and the TE group according to the time for the first analgesic requirement which starts after $6 \mathrm{hrs}$. in SAPB and after 4 hrs in TE group with (a P value of $<0.001$ ). This study goes with Arora $\boldsymbol{e t}$ al. ${ }^{(10)}$ who studied the Efficacy of Serratus Anterior Plane Block Versus Thoracic Paravertebral Block for Postoperative Analgesia in Breast Cancer Surgery. Forty ASA I or II patients in the age group of 18-60 years were randomized into either ultrasound-guided Thoracic Paravertebral block (TPVB) group $(\mathrm{N}=20)$ or Serratus Anterior plane block (SAPB) group $(\mathrm{N}=20)$. In the preoperative room, TPVB group patients received $0.4 \mathrm{ml} / \mathrm{kg}$ of $0.5 \%$ ropivacaine at the T4 level. Whereas patients in the SAPB group received $0.4 \mathrm{ml} / \mathrm{kg}$ of $0.5 \%$ ropivacaine at the 6 th intercostal space into the plane between the serratus anterior and the intercostal muscles.

As regard hemodynamic measurements (HR and MAP), the results of the current study showed that there was a nonsignificant difference found between the studied groups at baseline values (P-value > 0.899). while there was a highly statistically significant decrease from after block to $1 \mathrm{hr}$ after block. in TE group compared with SAPB group with (a P-value < 0.011). The results of the current study showed that there was a significant decrease in the incidence of hypotension and bradycardia in the SAPB group compared to the TE group.

In agreement with the results of this current study, a study done by Blanco et al. ${ }^{(4)}$ performed the SAPB block in 50 patients undergoing modified radical mastectomies, they reported that there is no change in hemodynamic with the SAPB block because there is no sympathetic block was associated with it as that is associated to epidural and paravertebral blockades.

Also, in agreement with the results of the current study Soni et al. ${ }^{(14)}$ compared thoracic epidural and paravertebral in patients undergoing breast surgery using single shots of $0.5 \%$ Ropivacaine. They found a significant 
change in MAP of the patient receiving epidural anesthesia at $10 \mathrm{~min}, 20 \mathrm{~min}, 30 \mathrm{~min}, 40 \mathrm{~min}, 50 \mathrm{~min}, 1 \mathrm{hr}, 1 \mathrm{hr} \mathrm{PO}$ (a $\mathrm{P}$-value $<0.05)$. They explained their finding as that the cardiac sympathetic fibers (T1 to T4) are blocked which may cause a decrease in cardiac contractility, Also, increased central venous pressure, splanchnic nerve blockade with blockade of medullary secretion of catecholamines, dilatation of the capacitance vessels of the lower limbs may also occur and the cardiovascular reflexes for responding to low cardiac output states are abolished. This can lead to profound hypotension and bradycardia.

In the present study, as regard side effects, no complications in the studied groups were recorded such as pneumothorax, vascular puncture, or local anesthetic toxicity. Postoperative nausea and vomiting, (PONV) can result in serious adverse effects extending the duration of hospital care with decreased patient satisfaction. In terms of PONV according to 5-point scale $(0-4)$, where $0=$ no nausea or vomiting, $1=$ mild nausea, $2=$ severe nausea, $3=$ vomiting once, and $4=$ vomiting more than once. In the present study, the number of patients who developed PONV was (4) patients in group A (GA) and (3) patients in group B (TE) and (2) patients in group C (SAPB) with (a P-value of 0.676) with no significant difference in between.

Also, a study done by Biswas et al. ${ }^{(15)}$ found that the incidence of nausea and vomiting was similar in epidural and paravertebral in thoracotomy patients. The use of opioids with LAs infusion may explain the similarity of the incidence.

Khalil $\boldsymbol{e t} \boldsymbol{a l} .{ }^{\left({ }^{(8)}\right.}$ study reported only one case of nausea in the SAPB group.

In contrast to this study a study done by Zhou $\boldsymbol{e t}$ al. ${ }^{(9)}$, the amount of vomiting after surgery was significantly lower in patients in the SAP block group compared to those in the control group. Most likely, the decrease in the incidence of vomiting resulted from the lower doses of IV opioids administered to the patients who received SAP block. Also, the addition of dexamethasone should have reduced the frequency of vomiting and nausea in Group 2 patients. And Shokri and Kasem (16) compared the Efficacy of postsurgical ultrasound-guided SAP block and wound infiltration on postoperative analgesia after female breast surgeries there was a significant difference between the study groups regarding the incidence of vomiting. Hards et al. (11) reported that nausea was well controlled in patients receiving a serratus plane block with no patients complaining of nausea, and all patients were mobilizing on the first day after their operation.

\section{CONCLUSION}

SAP block can produce excellent pain relief during the first six postoperative hours. It has great promise due to its simplicity, easy-to-learn techniques, and relative lack of contraindications and complications.

\section{REFERENCES}

1. Klein S, Bergh A, Steele $S$ et al. (2000): Thoracic paravertebral block for breast surgery. Anesthesia \& Analgesia, 90(6):1402-5.

2. Andersen K, Kehlet H (2011): Persistent pain after breast cancer treatment: a critical review of risk factors and strategies for prevention. The Journal of Pain, 12(7):725-46.

3. Priestley M, Cope L, Halliwell $\mathbf{R}$ et al. (2002): Thoracic epidural anesthesia for cardiac surgery: the effects on tracheal intubation time and length of hospital stay. Anesthesia \& Analgesia, 94(2):275-82.

4. Blanco R, Parras T, McDonnell J et al. (2013): Serratus plane block: a novel ultrasound-guided thoracic wall nerve block. Anaesthesia, 68(11):1107-13.

5. Fajardo M, López S, Diéguez $P$ et al. (2013): A new ultrasound-guided cutaneous intercostal branches nerves block for analgesia after non-reconstructive breast surgery. Cirugia Mayor Ambulatoria, 18:3-6.

6. Macea J, Fregnani J (2016): Anatomy of the thoracic wall, axilla, and breast. Int J Morphol., 24(4):691-704.

7. Marhofer P, Greher M, Kapral S (2012): Ultrasound guidance in regional anesthesia. British Journal of Anaesthesia, 94(1):7-17.

8. Khalil A, Abdallah N, Bashandy G et al. (2017): Ultrasound-guided serratus anterior plane block versus thoracic epidural analgesia for thoracotomy pain. Journal of Cardiothoracic and Vascular Anesthesia, 31(1):152-8.

9. Zhou Y, Huang J, Lu X et al. (2015): Patient-controlled intravenous analgesia for non-small cell lung cancer patients after thoracotomy. Journal of Cancer Research and Therapeutics, 11(5):128-133.

10.Arora S, Ovung R, Yaddanapudi S et al. (2016): Abstract PR481: efficacy of thoracic paravertebral block versus serratus intercostal plane block for postoperative analgesia in breast cancer surgery. Anesthesia \& Analgesia, 123(3):178-183.

11.Hards M, Harada A, Neville I et al. (2016): The effect of serratus plane block performed under direct vision on postoperative pain in breast surgery. Journal of Clinical Anesthesia, 34:427-31.

12. Davies R, Myles P, Graham J (2006): A comparison of the analgesic efficacy and side-effects of paravertebral vs epidural blockade for thoracotomy - a systematic review and meta-analysis of randomized trials. BJA: British Journal of Anaesthesia, 96(4):418-26.

13.Júnior A, Erdmann T, dos Santos T et al. (2013): Comparison between continuous thoracic epidural and paravertebral blocks for postoperative analgesia in patients undergoing thoracotomy: a systematic review. Brazilian Journal of Anesthesiology (English Edition), 63(5):433-42.

14.Soni S, Soni A, Bapugol M et al. (2015): Comparision of thoracic epidural block vs paravertebral block in patients undergoing breast surgery. Indian Journal of Clinical Anaesthesia, 2(1):48-56.

15. Biswas S, Verma R, Bhatia V et al. (2016): Comparison between the thoracic epidural block and thoracic paravertebral block for post-thoracotomy pain relief. Journal of Clinical and Diagnostic Research, 10(9):8-13.

16.Shokri H, Kasem A (2017): Efficacy of postsurgical ultrasound-guided serratus intercostal plane block and wound infiltration on postoperative analgesia after female breast surgeries. A comparative study. Egyptian Journal of Anesthesia, 33(1):35-40. 